\title{
Measuring the effect of a mobile coronary care unit upon the community
}

\author{
N. J. VETTER 1 , S. POCOCK², AND D. G. JULIAN \\ From Royal Infirmary, Edinburgh
}

SUMMARY A mobile coronary care unit working within a geographically defined area retrieved 20 per cent of the estimated number of cases with myocardial infarction. These cases were similar to the population at risk in terms of age, sex, and previous history of ischaemic heart disease.

Patients retrieved by the mobile unit had a lower overall case fatality ratio. This discrepancy was greater than could be explained by resuscitation or preventive treatment by the mobile unit teams. Reasons for this difference in mortality were explored.

The benefits of the mobile coronary care unit were obvious in terms of the existing service but small in terms of the community. Any judgment on the effectiveness of a mobile unit must use both approaches to get a balanced view.

Mobile coronary care units have been set up in many countries (Pantridge et al., 1975). Attitudes towards the founding of new units have varied. The British have been slow to develop them (Dewar, 1975), whereas in the United States the trend has been towards complex systems capable of reaching patients within minutes (Cobb et al., 1975; Nagel et al., 1975).

Mobile coronary care units are a response to a problem: the large number of deaths from ischaemic heart disease in the community before medical aid can be obtained. Their effectiveness depends entirely upon their ability in meeting this problem. However most research work into the use of mobile coronary care units has concentrated on patients seen in and treated by the units, ignoring the community at large from which these patients were drawn. The present study was set up in order to measure the impact of a mobile coronary care unit upon the population with ischaemic heart disease in a defined area.

\section{Patients}

Two hundred and twenty-seven patients, initially suspected of having had a myocardial infarction,

1Present address: Research Team for the Care of the Elderly, St Davids Hospital, Cowbridge Road East, Cardiff.

2Present address: Department of Clinical Epidemiology, Royal Free Hospital, London NW3.

Received for publication 26 June 1978 were seen by the mobile coronary care unit in a period of 14 months. One hundred and fifty-eight were proved to have had a myocardial infarction and a further 10 had a history strongly suggestive of infarction but died before a definitive diagnosis could be made. This 168 comprised the study group; 117 were men, 51 were women. Their mean age was 57.5 years, with an upper limit of 69 years.

The patients in the study were restricted to those retrieved from a defined area of 12 electoral wards in the south of Edinburgh, the traditional catchment area for the Royal Infirmary, at which the mobile unit was based. Two hundred and six general practitioners whose practices were wholly or partially in this area were contacted and informed that any patient suspected of having had a myocardial infarction living within these wards would be eligible for treatment by the mobile unit. A proviso was added that any patient from outside the area whom the general practitioner considered required urgent treatment by the mobile coronary care unit would be attended. The latter patients were not included in the present study.

No specific interventions were made regarding treatment of the patients other than those indicated by the therapeutic schedule for the hospital coronary care unit (Lawrie et al., 1967). This most often involved giving analgesics; morphine $10 \mathrm{mg}$ and cyclizine $50 \mathrm{mg}$ usually given slowly intravenously until pain was substantially relieved. Atropine was given for sinus bradycardia if the patient's blood pressure fell below $90 \mathrm{mmHg}$ or 
ectopic beats were seen. The only other drug frequently given was lignocaine for close-coupled ( $R$ on $T$ ) ectopic beats or ventricular tachycardia.

\section{RETRIEVAL OF PATIENTS}

Patients were usually referred to the unit by their general practitioners. If a patient telephoned his or her general practitioner with a history suggestive of ischaemic heart disease the doctor was encouraged to call the mobile coronary care unit directly before seeing the patient. If the patient had had over 20 minutes of chest pain or sudden breathlessness or syncope, he or she was admitted to the hospital coronary care unit in the mobile unit. No patient refused admission if it was advised.

Staffing of the unit was carried out by 7 postregistration doctors with an interest in ischaemic heart disease. They also covered the hospital coronary care unit for the insertion of emergency pacing catheters.

\section{Results}

The population, from which the study group was drawn, was defined as those people living in an area to the south of the city of Edinburgh enclosed by 12 voting wards. The area measured 10 miles by 5 and contained 249700 people-approximately 55 per cent of the population of the city.

The mobile coronary care unit had an upper imposed age limit of 69 years because of the policy of the hospital coronary care unit at which it was based; no patients were retrieved under 20 years of age. An estimate was made of the number of people in this population who had had an attack of ischaemic heart disease. This was made using data from the Edinburgh community study (Armstrong et al., 1972) which was performed 3 years before. There was no pronounced change in the mortality from ischaemic heart disease over that period in Edinburgh, being 4.54 per 1000 for people between 35 and 75 years of age during the community study and 4.58 per 1000 in the year of the present study. It was, therefore, inferred that the morbidity from ischaemic heart disease during that period had not varied greatly.

Episode rates of ischaemic heart disease were taken from the community study and multiplied by the population at risk to give the expected number of attacks.

During the community study it was discovered that some of the most important data on patients with ischaemic heart disease were hidden in 2 ways. One group, the unattended deaths, was obtained by examining the death certificates of patients; the other group had insufficient data for a definitive diagnosis but some subjective evidence that the patients had sustained a myocardial infarction. As both groups of patients had died very soon after the onset of their symptoms, they were included in the comparison with the service which was aimed at the retrieval of such early deaths. The estimated numbers in the present study include both of these groups.

Eight hundred and thirty-six episodes of myocardial infarction were estimated to have occurred in the catchment area of the mobile coronary care unit during the period of the study. In fact the unit attended $168(21 \%)$ patients with myocardial infarction or sudden death.

The small proportion of cases actually carried by the mobile unit made it essential to test, as far as possible, the degree to which the study group was typical of the population in the study area with myocardial infarction. In particular any factors liable to affect the case fatality ratios of the two groups required to be examined.

Several categories of these data were examined: demographic, social, previous history, and factors with special relevance to the mobile unit, the time, and place of the attack.

\section{DEMOGRAPHIC DATA}

Table 1 shows the age and sex breakdown of the patients with myocardial infarction seen in the mobile coronary care unit compared with those attacks of myocardial infarction estimated to have occurred over the same period in the community. Despite the low proportion of patients seen by the mobile unit, their age and sex categories were very similar to those expected from the community data. Age and sex are known to be related to the outcome of an attack. Armstrong et al. (1972) have shown increasing fatality ratios with age and a slightly higher ratio in women than men.

The relation between mortality and social factors is more complex. Standardised mortality ratios are lower in Scotland for the higher groups in the Registrar General's social class classification, but this may reflect a variation in the attack rate. A paper by Colling et al. (1976) was one of the few to describe community morbidity in terms of social class and found a high proportion of social class I and II. They did not relate these findings to mortality. However, social factors normally play such an all-pervading part in the prevalence of disease that it was thought to be important to describe the study group in this way. In this study group social classes I and II had a lower case fatality ratio $(15 \%)$ than social classes IV and V $(29 \%)$ though these differences were not significant at a 5 per cent level.

Table 2 shows the study group by social class 
Table 1 Observed and expected episodes of myocardial infarction in the population at risk

\begin{tabular}{|c|c|c|c|c|c|c|c|c|c|}
\hline & \multicolumn{4}{|l|}{ Men } & \multicolumn{4}{|c|}{ Women } & \multirow[t]{2}{*}{ All } \\
\hline & $20-$ & $50-$ & $60-69$ & Total & $20-$ & $50-$ & $60-69$ & Total & \\
\hline $\begin{array}{l}\text { Population (1000s) } \\
\text { Observed (in MCCU) } \\
\text { Expected } \\
\text { (from Community study) } \\
\text { Proportion observed (\%) }\end{array}$ & $\begin{array}{l}45 \cdot 3 \\
19 \\
97 \cdot 1\end{array}$ & $\begin{array}{c}13 \cdot 2 \\
45 \\
205 \cdot 1\end{array}$ & $\begin{array}{c}11 \cdot 9 \\
52 \\
288 \cdot 9\end{array}$ & $\begin{array}{l}70 \cdot 4 \\
116 \\
591 \cdot 1\end{array}$ & $\begin{array}{l}47 \cdot 9 \\
5 \\
16 \cdot 7\end{array}$ & $\begin{array}{l}16 \cdot 2 \\
15 \\
60 \cdot 9\end{array}$ & $\begin{array}{c}16 \cdot 2 \\
31 \\
142 \cdot 1\end{array}$ & $\begin{array}{c}80 \cdot 3 \\
51 \\
219 \cdot 7\end{array}$ & $\begin{array}{l}150 \cdot 7 \\
167^{\star} \\
810 \cdot 8\end{array}$ \\
\hline
\end{tabular}

^Age not known in 1 male patient.

Table 2 Comparison of social class groupings of study group and other groups with ischaemic heart disease

\begin{tabular}{lrrrrr}
\hline \multicolumn{5}{c}{ Social class (\%) } \\
\cline { 2 - 6 } & \multicolumn{1}{c}{$I I$} & $I I I$ & $I V$ & \multicolumn{1}{l}{ V } \\
\hline Study group & 4.3 & $31 \cdot 2$ & 46.4 & 15.9 & $2 \cdot 2$ \\
Study population & 7.9 & $12 \cdot 1$ & 57.4 & 13.5 & $9 \cdot 1$ \\
Cay et al. (1972) & 4.4 & 20.7 & 31.0 & 25.1 & 18.7 \\
(hospital) & & & & & \\
Colling et al. (1976) & 14.7 & 17.4 & 59.4 & 13.7 & 4.9 \\
Edinburgh mortality & 7.7 & 11.5 & 60.8 & 13.0 & 10.2 \\
\hline
\end{tabular}

Goodness of fit test: study group vs study population.

$x^{2}{ }_{4}=65 \cdot 2, P<0.0001$, that is highly significant difference in composition by social class.

compared with the general population in the study area, hospital patients in Edinburgh with ischaemic heart disease (Cay et al., 1972), the Teesside community study (Colling et al., 1976), and deaths from myocardial infarction in Edinburgh. The study group appears to have an excess of people in social class II and a low proportion of social class V. This together with the relatively low case fatality in the higher social classes suggest that general practitioners were calling the mobile unit selectively for people in social class II.

\section{PREVIOUS HISTORY OF HEART DISEASE}

A previous history of heart disease has been shown to have a relation with prognosis in several hospitalbased indices (Peel et al., 1962; Norris et al., 1969), and in civil servants in the community (Rose $e t$ al., 1977). Table 3 shows the proportion of patients with a previous history of heart disease in 2 community studies (Armstrong et al., 1972; Tunstall-Pedoe et $a l ., 1975)$ and the overall figure for the WHO community registers (WHO, 1976).

The study group differed from the community figures in its higher proportion of patients with long-standing angina. This would be expected to have less effect on prognosis than angina of recent onset. The Table shows that, in the latter case, the study group had a proportion of patients affected similar to that seen in the WHO study.
Table 3 Comparison of previous cardiac disease between study group and other community data (\%)

\begin{tabular}{llll}
\hline & $\begin{array}{l}\text { Previous } \\
\text { infarction }\end{array}$ & $\begin{array}{l}\text { Previous } \\
\text { angina }\end{array}$ & $\begin{array}{l}\text { Increased } \\
\text { angina } \\
(1 / 12)\end{array}$ \\
\hline $\begin{array}{l}\text { Study group } \\
\begin{array}{l}\text { Edinburgh community study } \\
\text { (Armstrong et al., 1972) }\end{array}\end{array}$ & 32 & 69 & 32 \\
$\begin{array}{l}\text { Tunstall-Pedoe et al. (1975) } \\
\text { WHO Registers (WHO, 1976) }\end{array}$ & 35 & - & - \\
\hline
\end{tabular}

Goodness of fit: previous angina for study group vs WHO registers: $\chi^{2}{ }_{1}=12 \cdot 1, \mathrm{P}<0.0005$, that is highly significant difference in attack rate.

SPACE AND TIME

By the nature of the service it might be expected that patients at a distance from the base station would be less likely to be retrieved. Some general practitioners might have considered that the time taken for the mobile unit to arrive would undermine its usefulness to patients at a distance.

The cases retrieved were examined by their electoral ward of residence and the proportion of observed cases compared with the numbers expected. The expected cases were calculated from the age and sex structure of each ward using the episode rates from the community study. There was no pattern of under- or over-usage of the mobile unit in relation to the distance from the Royal Infirmary (mean $20.1 \%$; standard deviation for 12 wards, $3 \cdot 1 \%)$.

The general practitioners who called the unit were biased against using it at night. The World Health Organisation myocardial infarction community registers showed that 53 per cent of all attacks of myocardial infarction began in daytime (06001800); Tunstall-Pedoe et al. (1975) also showed 52 per cent starting within that time. In the present study group 70 per cent of patients had the onset of their attacks between these hours. There were no differences of this type for the day of the week or the month of the year.

These variations in time and space were not use- 
Table 4 Outcome-cardiac arrests and non arrests

\begin{tabular}{|c|c|c|c|c|c|c|c|}
\hline & & \multicolumn{3}{|l|}{ Men } & \multicolumn{2}{|c|}{ Women } & \multirow{2}{*}{$\begin{array}{l}\text { Total } \\
20-69\end{array}$} \\
\hline & & $20-$ & $50-$ & $60-69$ & $20-$ & $60-69$ & \\
\hline \multirow[t]{2}{*}{ No cardiac arrest within 4 weeks } & & 19 & 29 & 33 & 16 & 21 & 118 \\
\hline & Arrested at home & 0 & 3 & 3 & 1 & 3 & 10 \\
\hline \multirow{3}{*}{ Survivors of cardiac arrest within 4 weeks } & Arrested in MCCU & 0 & 0 & 0 & 0 & 0 & 0 \\
\hline & $\begin{array}{l}\text { Arrested in hospital } \\
\text { Total }\end{array}$ & 0 & 3 & 3 & 1 & 1 & 8 \\
\hline & Arrested at home & 0 & 4 & 4 & 2 & 1 & 1120 \\
\hline \multirow{2}{*}{ Died of cardiac arrest within 4 weeks } & Arrested in MCCU & 0 & 0 & 0 & 0 & 0 & 0 \\
\hline & Arrested in hospital & 0 & 6 & 10 & 0 & 5 & 21 \\
\hline Overall total & (Total & $\begin{array}{r}0 \\
19\end{array}$ & $\begin{array}{l}10 \\
45\end{array}$ & $\begin{array}{l}14 \\
53\end{array}$ & $\begin{array}{r}2 \\
20\end{array}$ & $\begin{array}{r}6 \\
31\end{array}$ & $\begin{array}{r}32 \\
168\end{array}$ \\
\hline
\end{tabular}

Three patients arrested at home and again in hospital: 2 survived 4 weeks, 1 died.

Counted in first place of attack only.

ful for assessing the relative severity of the study group against the community, for the relation between those variables and severity of disease is unknown. The time of onset made little difference to the outcome, for the patients seen by the mobile unit had a mortality of 19 per cent in the day-time compared with 20 per cent for those whose symptoms began at night. These factors do however highlight the unexpected ways in which such a system may cause bias and the degree to which this can cause differences between patients retrieved and the community at large.

\section{OUTCOME}

Table 4 shows the patients in the study group classified by whether or not they suffered a cardiac arrest. These are also categorised by the place of their first arrest and by age/sex groups. Ten of the patients who arrested at their place of attack died there and a definitive diagnosis of myocardial infarction could not be made on these patients. One other survived the initial arrest at the place of the attack but died later in hospital.

There was an increased proportion of cardiac arrests among the older age groups. The greatest percentage was seen in men aged 60 to 69 , with $20 / 53$ $(38 \%)$ suffering an arrest at some time, of whom 14 died. Overall, $32 / 168(19 \%)$ of patients died within 4 weeks of the onset of their symptoms; the majority (30) at the place of the original arrest.

Resuscitation was successfully carried out in 18 patients. In 10 this was initiated at the place of onset of the attack and was carried out by the mobile unit team. A further 8 patients were successfully resuscitated after a first arrest in hospital. No cardiac arrests occurred in the mobile coronary care unit while it was transporting patients to hospital, nor did any occur as the patient was being moved into the mobile unit.

The incidence of cardiac arrests is closely related to the time after the onset of a patient's symptoms. Table 5 shows these data for the study group. Thirteen $/ 47(29 \%)$ of patients seen initially within an hour of the onset of their symptoms had a cardiac arrest when they were first seen at home by the mobile unit team. This compared with $5 / 76(7 \%)$ for patients first seen between 1 and 4 hours and $2 / 42(5 \%)$ after 4 hours.

\section{OUTCOME-COMPARISON BETWEEN STUDY \\ GROUP AND COMMUNITY}

Thirty-two of 168 patients (19\%) seen by the mobile coronary care unit died within 4 weeks of the onset of their symptoms compared with 42 per cent expected from the community data. This difference was not the result of resuscitation by the mobile unit for if the successfully resuscitated cases had died there would have been 43 deaths (25\%), still significantly less than the proportion expected in the community.

The major determinant of mortality after myocardial infarction is the time after the onset of the acute event. It was likely to be a major source of bias when comparing a retrospective community survey with a group entering the study at different times after medical aid had been summoned.

Table 6 illustrates this. The first section (A) shows data from the community survey, with the deaths in time intervals after the onset of the patient's symptoms. The next (B) shows data for the patients seen in the mobile coronary care unit. The third (C) shows the same data with all cardiac arrests in the mobile unit, including those successfully resuscitated, counted as deaths. This group was included to test the effect of resuscitation by the mobile unit. See appendix for a more detailed explanation of Table 6.

It is an inevitable limitation of this study that the small numbers at risk make the figures for patients seen in the first hour particularly susceptible to bias. 
Table 5 Outcome-time patients initially seen after onset of symptoms related to patients with and without cardiac arrest

\begin{tabular}{|c|c|c|c|c|}
\hline Place of event & At home & Hospital CCU & Hospital rvard & Returned home \\
\hline $\begin{array}{l}\text { Time after onset } 0-1 \text { hours } \\
\text { Number of patients } \\
\text { Cardiac arrests } \\
\text { Died } \\
\text { Resuscitated }\end{array}$ & $\left.\begin{array}{l}97 \longrightarrow \\
4\end{array}\right\} 13$ & $\left.\begin{array}{l}5 \\
5\end{array}\right\} 10$ & $\left.\begin{array}{l}2 \\
0\end{array}\right\} 2$ & 31 \\
\hline $\begin{array}{l}\text { Time after onset } 1-4 \text { hours } \\
\text { Number of patients } \\
\text { Cardiac arrests } \\
\text { Died } \\
\text { Resuscitated }\end{array}$ & 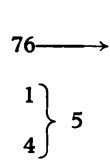 & $\left.\begin{array}{l}75 \longrightarrow \\
9 \\
3\end{array}\right\} 12$ & $\left.\begin{array}{l}36 \longrightarrow \\
0\end{array}\right\} 3$ & 63 \\
\hline $\begin{array}{l}\text { Time after onset over } 4 \text { hours } \\
\text { Number of patients } \\
\text { Cardiac arrests } \\
\text { Died } \\
\text { Resuscitated }\end{array}$ & $\left.\begin{array}{l}42 \longrightarrow \\
2\end{array}\right\} 2$ & $\left.\begin{array}{l}42-\rightarrow \\
1 \\
0\end{array}\right\} 1$ & $\left.\begin{array}{l}41 \longrightarrow \\
2 \\
0\end{array}\right\} 2$ & 39 \\
\hline
\end{tabular}

Data of time after onset not available for 3 patients.

This, together with the large number of cardiac arrests within this time interval resulted in extremely high case fatality ratios compared with the number expected. Two factors probably played a part in this; firstly the mobile unit was called more quickly to patients who had already arrested than to those who had not. As arrests were more common within the first hour the mobile unit saw a disproportionate number of them at that time. Secondly, the patients at risk entered the study for an average of only $17 \cdot 4$ minutes in the first hour. Some patients had arrested before they officially entered the study, when the mobile unit arrived, artificially increasing the observed number of arrests compared with the average number of patients at risk. This problem could be avoided by counting only cardiac arrests which occurred after the mobile unit arrived. In either case no proper comparison can be made for this group between the mobile unit patients and the community other than to say that there were many cardiac arrests within the first time interval in all groups.

For the remaining time ( 1 hour to 4 weeks) 23 patients died in the mobile unit compared with 40.9 expected. This difference was highly statistically significant $(P=0.005)$. If resuscitation by the mobile unit was ignored the number of deaths was still less than expected, with 29 observed against $38 \cdot 1$ expected, but the difference was not statistically significant $(P=0 \cdot 13)$.

\section{Discussion}

This was an observational study of the use of a mobile coronary care unit within a defined area.
These data were compared with morbidity and mortality figures from the community obtained some years earlier. In this way it was hoped to put the work of the mobile unit into a community context.

The unit team attended 20 per cent of the estimated number of cases in the community. This small proportion reflected several factors.

The Edinburgh Community Study showed that general practitioners in Edinburgh chose initially to treat 31 per cent of all episodes of ischaemic heart disease at home. An unknown proportion of patients came directly to hospital by their own transport and in up to 4 per cent the attack will have started in hospital (Tunstall-Pedoe et al., 1975). The mobile unit was a new service at the start of this study and such services take some time to become accepted. The Belfast workers (Pantridge et al., 1975) retrieved increasing numbers of patients each year over the first 4 years of the service.

The patients seen by the mobile unit were similar in age and sex, previous history of heart disease, and place of the acute attack, to the population with ischaemic heart disease. There were differences in social class structure and the time of day of the attack. This suggests that general practitioners were using the unit selectively for the higher social class patients and those seen in the day-time. General practitioners were expected to stay with a patient if they called the mobile unit; thus calling the unit was more time consuming than calling a city ambulance. This may have caused some of the bias against the unit at night.

The factors measured in order to compare the structure of the two groups were obviously not good 
sble 6 Comparison between study group and community at various time intervals after onset of symptoms (see Appendix)

\begin{tabular}{|c|c|c|c|c|c|c|c|c|c|c|c|c|c|}
\hline \multirow{2}{*}{$\begin{array}{l}\text { ne interval } \\
\text { urs after onset) }\end{array}$} & \multicolumn{3}{|c|}{ Community data $A$} & \multicolumn{5}{|c|}{ Study group B } & \multicolumn{5}{|c|}{ Study group $C$} \\
\hline & $\begin{array}{l}\text { Alive at } \\
\text { beginning }\end{array}$ & Died & $\begin{array}{l}\text { Proportion } \\
\text { who died }\end{array}$ & $\begin{array}{l}\text { Seen at } \\
\text { beginning }\end{array}$ & $\begin{array}{l}\text { Entered } \\
\text { study }\end{array}$ & $\begin{array}{l}\text { Average } \\
\text { no. at risk }\end{array}$ & Died & $\begin{array}{l}\text { *Expected } \\
\text { no. of } \\
\text { deaths }\end{array}$ & $\begin{array}{l}\text { Seen at } \\
\text { beginning }\end{array}$ & $\begin{array}{l}\text { Entered } \\
\text { study }\end{array}$ & $\begin{array}{l}\text { Average } \\
\text { no. at } \\
\text { risk }\end{array}$ & $\begin{array}{l}\text { Died + } \\
M C C U \\
\text { arrests }\end{array}$ & $\begin{array}{l}\text { ^Expected } \\
\text { no. of } \\
\text { deaths }\end{array}$ \\
\hline $\begin{array}{l}-1 \\
-2 \\
-4 \\
-6 \\
-12 \\
-24 \\
-48 \\
-4 \text { weeks } \\
\text { ital }\end{array}$ & $\begin{array}{r}1010 \\
818 \\
797 \\
771 \\
753 \\
724 \\
700 \\
672\end{array}$ & $\begin{array}{r}192 \\
21 \\
26 \\
18 \\
29 \\
24 \\
28 \\
84\end{array}$ & $\begin{array}{l}0.190 \\
0.025 \\
0.033 \\
0.023 \\
0.039 \\
0.03 \\
0.04 \\
0.125\end{array}$ & $\begin{array}{r}0 \\
38 \\
81 \\
112 \\
128 \\
141 \\
145 \\
140\end{array}$ & $\begin{array}{r}47 \\
43 \\
33 \\
17 \\
14 \\
8 \\
3 \\
0\end{array}$ & $\begin{array}{r}13.6 \\
59.5 \\
97.5 \\
120.5 \\
135.0 \\
145.0 \\
146.5 \\
140.0\end{array}$ & $\begin{array}{r}9 \\
0 \\
2 \\
1 \\
1 \\
4 \\
8 \\
7 \\
23\end{array}$ & $\begin{array}{r}2 \cdot 6 \\
1 \cdot 5 \\
3 \cdot 2 \\
2 \cdot 8 \\
5 \cdot 2 \\
4 \cdot 8 \\
5 \cdot 9 \\
17 \cdot 5 \\
40 \cdot 9\end{array}$ & $\begin{array}{r}0 \\
34 \\
74 \\
104 \\
118 \\
131 \\
135 \\
130\end{array}$ & $\begin{array}{r}47 \\
43 \\
33 \\
17 \\
14 \\
8 \\
3 \\
0\end{array}$ & $\begin{array}{r}13.6 \\
55.5 \\
90.5 \\
112.5 \\
125.0 \\
135.0 \\
136.5 \\
130.0\end{array}$ & $\begin{array}{r}13 \\
3 \\
3 \\
3 \\
1 \\
4 \\
8 \\
7 \\
29\end{array}$ & $\begin{array}{r}2.6 \\
1.4 \\
3.0 \\
2.6 \\
4.8 \\
4.5 \\
5.5 \\
16 \cdot 3 \\
38 \cdot 1\end{array}$ \\
\hline
\end{tabular}

xpected no. of deaths $=$ proportion who died in the community $\times$ average no. at risk. ita of time after onset not available for 3 patients.

predictors of deaths in this group of patients. This may have been because these patients were seen soon after the onset of their symptoms when a high proportion of the deaths resulted from sudden arrhythmias. Kannel et al. (1975) have shown that prediction of these early deaths was notoriously difficult using clinical and demographic data.

Comparison of the outcome between the study group and the community was complicated by the different nature of the two sets of data. Unlike the retrospective community data the mobile unit patients were not all present at the beginning of the study, but were admitted throughout, subtly altering the characteristics of the group with time.

The difficulties of this comparison were greatest for the first hour group where the largest number of deaths and the greatest acceleration of admissions occurred. These fluctuations proved too much for the accurate comparison of the fatality ratios. A partial answer would be to break down the initial time interval into small segments and to count only arrests occurring after the arrival of the mobile unit, but these data were not available from the community study.

The mobile unit patients had a similar fatality ratio to the population at risk between 1 hour and 48 hours, if the effect of resuscitation by the mobile unit was discounted (Table 6C), suggesting that the groups were comparable during that time. If this was the case only resuscitation had any effect upon the community mortality-prophylactic measures, for example antiarrhythmic therapy in the mobile unit, did not significantly reduce the mortality during the time interval to below that seen in the community. After 48 hours there was a reduced number of observed deaths compared with the number expected. The reason for this is not fully understood but it was unlikely to be an effect of the mobile unit at the time.
A recent randomised trial of a mobile coronary care unit (Hampton and Nicholas, 1978) failed to show an advantage of a mobile coronary care unit over a routine ambulance for collecting patients with heart attacks; but only 1 of the 82 patients who arrested in the community survived hospital stay. This is a much lower proportion than has been seen in other studies including the present one (Adgey and Pantridge, 1977; Cobb et al., 1975; Mackintosh et al., 1978), and suggests that they have been unlucky with their patient selection.

One previous study (Crampton et al., 1975) has attempted to relate the effects of a mobile unit to community mortality. They claimed an association between a falling death rate from myocardial infarction and the inception of a mobile unit. However, there was no good evidence that the changes were cause and effect, particularly as the mortality rate from ischaemic heart disease was falling rapidly over the years before the introduction of the unit in the community studied.

The relation between a service effect and the community it serves is complex. Thus the mobile unit in this study resuscitated 6 per cent of its patients with myocardial infarction when still in the community compared with 7 per cent in the hospital unit if the units had no adverse effect. However, the mobile unit saw only 20 per cent of the estimated number of people with myocardial infarction in the community giving an overall reduction in the mortality rate of, at most, 1.2 per cent over 4 weeks. The effect upon the Registrar General's annual mortality figures will be well within the random changes expected from environmental factors from year to year. Nor would such differences be detected by a community study of manageable size.

The proportion of patients retrieved could have been increased by administrative changes: taking calls directly from the public and education in 
resuscitation methods have had an effect elsewwhere (Black and Brown, 1973). Alternatively the resources used by the service can be increased. This has been attempted in several places, notably Seattle where 3 mobile coronary care units and several back-up units were combined with a massive public education programme in resuscitation.

Using these resources the Seattle group attended 55.3 persons per 100000 population per annum with 9.6 per 100000 saved each year. The equivalent in this study was 5.4 persons seen and 2.9 per 100000 saved. Thus the Seattle group was able to save 3 times the number of patients compared with the Edinburgh unit.

Within the realms of the possible the mobile coronary care unit is the only available method of treating a cardiac arrest in the community. Whether a mobile unit is worth having in a community is a value judgment which must be based upon the balance of its success with the patients it retrieves, its failure to reach many requiring help, and the resources available. This paper has emphasised that this is not a simple exercise.

Dr Vetter was supported by a grant from the Scottish Hospitals Endowment Research Trust.

\section{Appendix}

Section A of Table 6 shows data from the Edinburgh community study (Armstrong et al., 1972) with the proportion of patients who died within each time interval. Sections $B$ and $C$ are similar to each other. In the first column, 'seen at beginning', is entered the number of patients in the study group seen alive at the beginning of the time interval. The second column 'entered study' shows the number of patients with myocardial infarction first seen by the mobile unit within that time interval. The third column 'average no. at risk' relates to the average number of patients at risk of dying during the time interval.

As patients are entering the study, that is being retrieved by the mobile unit, throughout the time intervals the average number at risk is the number present halfway through any one time interval if one assumes that patients are being admitted at a fairly constant rate. This assumption was true after the first hour. Thus from 1 hour onwards this column is equal to the number of patients present at the beginning of the time interval plus half of those entering the study during that time.

The fourth column shows the number of patients who died in the time interval; for section $C$, patients who arrested in the home are counted as deaths. The last column in sections B and C shows the 'expected no. of deaths' which is the proportion who died at that time in the community multiplied by the average number at risk. This is an estimate of the number of deaths which would occur in the patients at risk in the study group during each time interval if there was a similar proportion of deaths to that seen in the community.

Patients seen by the mobile unit within an hour of the onset of their symptoms were not seen at a constant rate; few were seen within the first 30 minutes because of the inevitable delays in calling the mobile unit. Indeed the average time for retrieval for patients seen at under 1 hour after the onset of symptoms was 43.6 minutes. Thus the average exposure time of the study group entering at under 1 hour was 43.6 to 60 minutes or 17.4 minutes. The 'average number at risk' in the third column is, therefore, $\frac{17.4}{60} \times 47=13 \cdot 6$.

\section{References}

Adgey, J., and Pantridge, J. F. (1977). In Coronary Care in the Community, ed A. Colling Croom. Helm, London.

Armstrong, A., Duncan, B., Oliver, M. F., Julian, D. G., Donald, K. W., Fulton, M., Lutz, W., and Morrison, S. L. (1972). Natural history of acute coronary attacks. British Heart fournal, 34, 67-80.

Black, L. A., and Brown, D. D. (1973). Public information and heart attack: report of an educational program. Ohio State Medical fournal, 69, 369-374.

Cay, E. L., Vetter, N. J., Philip, A. E., and Dugard, P. (1972). Psychological reactions to a coronary care unit. Fournal of Psychosomatic Research, 16, 437-447.

Cobb, L. A., Baum, R. S., Alvarez, H., III, and Schaffer, W. A. (1975). Resuscitation from out-of-hospital ventricular fibrillation: 4 years follow-up. Circulation, 51 and 52, Suppl. III, 223-235.

Colling, A., Dellipiani, A. W., Donaldson, R. J., and McCormack, P. (1976). Teesside coronary survey: an epidemiological study of acute attacks of myocardial infarction. British Medical fournal, 2, 1169-1172.

Crampton, R. S., Aldrich, R. F., Gasco, J. A., Miles, J. R., Jr., and Stillerman, T. (1975). Reduction of pre-hospital and community coronary deaths by the community-wide emergency cardiac care system. American fournal of Medicine, 58, 151-165.

Dewar, H. A. (1975). The problems of coronary ambulances. fournal of the Royal College of Physicians of London, 9, 173181.

Hampton, R. J., and Nicholas, C. (1978). Randomised trial of a mobile coronary care unit for emergency calls. British Medical fournal, 1, 1181-1121.

Kannel, W. B., Doyle, J. T., McNamara, P. M., Quickenton, P., and Gordon, T. (1975). Precursors of sudden coronary death. Circulation, 51, 606-613.

Lawrie, D. M., Greenwood, T. W., Gcddard, M., Harvey, A. C., Donald, K. W., Julian, D. G., and Oliver, M. F. (1967). A coronary care unit in the routine management of acute myocardial infarction. Lancet, 2, 109-114.

Mackintosh, A. F., Crabb, M. E., Grainger, R., Williams, J. H., and Chamberlain, D. A. (1978). The Brighton resuscitation ambulances: review of $\mathbf{4 0}$ consecutive survivors of out-of-hospital cardiac arrest. British Medical fournal, 1, 1115-1118. 
Nagel, E. L., Liberthson, R. R., Hirschman, J. C., and Nussenfeld, S. R. (1975). Emergency care. Circulation, 51 and 52, Suppl. III, 216-222.

Norris, R. N., Brandt, P. W. T., Caughey, D. E., Lee, A. J., and Scott, P. J. (1969). A new coronary prognostic index. Lancet, 1, 274-278.

Pantridge, J. F., Adgey, A. A. G., Geddes, J. S., and Webb, S. W. (1975). The Acute Coronary Attack. Pitman Medical, Tunbridge Wells.

Peel, A. A. F., Semple, T., Wang, I., Lancaster, W. M., and Dall, J. L. G. (1962). A coronary prognostic index for grading the severity of infarction. British Heart fournal, 24, 745-760.

Rose, G., Reid, D. D., Hamilton, P. J. S., McCartney, P. Keen, H., and Jarrett, R. J. (1977). Myocardial ischaemia risk factors and death from coronary heart disease. Lancet, 1, 105-109.

Tunstall-Pedoe, H., Clayton, D. ,Morris, J. N., Brigden, W., and McDonald, L. (1975). Coronary heart attacks in East London. Lancet, 2, 833-838.

World Health Organization. Regional Office for Europe. (1976). Myocardial infarction community registers. Public health in Europe No. 5. World Health Organization, Copenhagen.

Requests for reprints to Dr N. J. Vetter, Welsh National School of Medicine, St Davids Hospital, Cowbridge Road, Cardiff CF1 9TZ. 